\title{
Proposed local diagnostic reference levels in angiography and interventional neuroradiology and a preliminary analysis according to the complexity of the procedures
}

\author{
Loredana D’Ercole $^{a, *}$, Federico Zappoli Thyrion ${ }^{b}$, Milena Bocchiola ${ }^{a}$, \\ Laura Mantovani ${ }^{a}$, Catherine Klersy ${ }^{c}$
}

a Department of Medical Physics, Fondazione IRCCS San Matteo Hospital, 27100 Pavia, Italy

b Department of Radiology, Fondazione IRCCS San Matteo Hospital, 27100 Pavia, Italy

c Service of Biometry and Clinical Epidemiology, Scientific Direction Fondazione IRCCS San Matteo Hospital, 27100 Pavia, Italy

Received 15 April 2010; received in revised form 23 September 2010; accepted 14 October 2010

Available online 11 November 2010

\section{KEYWORDS}

Cerebral angiography;

Cerebral embolisation;

Diagnostic reference

levels;

KAP (kerma-area

product)

\begin{abstract}
The aim of this study was to propose local diagnostic reference levels (DRL) for exposure to radiation during diagnostic procedures and neuroradiological interventions such as cerebral angiography and embolisation of cerebral aneurysms (intra-cranial aneurysms and arteriovenous malformations). Hospitals should adopt the national DRLs for use locally or establish their own DRLs based on local practice, if sufficient local data are available.

For this purpose we studied a sample of 113 cerebral angiography procedures and 82 embolisations of cerebral aneurysms. The data recorded included the kerma-area product (KAP), the fluoroscopy time and the number of frames for each procedure: third quartiles from the total dosimetric databank were calculated and proposed as provisional local DRL. Since the complexity of a procedure must be taken into account when evaluating the radiation dose, in the case of embolisation of aneurysms (intra-cranial), in this initial phase we assessed whether the complexity of the embolisation procedure is related to the size of the aneurysm and/or its site. We, therefore, re-calculated the DRL for only intra-cranial aneurysms, leaving aside the arteriovenous malformations. Considering that the DRL calculated for all the
\end{abstract}

\footnotetext{
* Corresponding author. Fondazione IRCCS San Matteo Hospital, Department of Medical Physics, Viale Golgi 19, 27100 PAVIA. Tel.: +39 0382503841; fax: +39 0382503036.

E-mail address: l.dercole@smatteo.pv.it (L. D’Ercole).
} 
therapeutic procedures are similar to those calculated considering only intra-cranial aneurysms, at the moment we propose, besides the DRL for cerebral angiography, a single DRL for all interventional procedures, even when the clinical pictures are very different. Local preliminary DRLs were proposed as follows: $180 \mathrm{~Gy} \mathrm{~cm}^{2}, 12 \mathrm{~min}$ and 317 frames for cerebral angiography and $487 \mathrm{~Gy} \mathrm{~cm}^{2}, 46 \mathrm{~min}$ and 717 frames for interventional procedures (intracranial aneurysms and arteriovenous malformations).

(c) 2010 Associazione Italiana di Fisica Medica. Published by Elsevier Ltd. All rights reserved.

\section{Introduction}

The EURATOM Directive 97/43 [1] on medical exposure states the need to establish and use diagnostic reference levels (DRL), defined as "dose levels in medical radiodiagnostic practices... for typical examinations for groups of standard-sized patients or standard phantoms for broadly defined types of equipment. These levels are expected not to be exceeded for standard procedures when good and normal practice regarding diagnostic and technical performance is applied". DRL are values of doses accepted for radiographic examinations [2-6] and their application is generally accepted for some diagnostic procedures with fluoroscopy, such as barium enemas and barium meals $[7,8]$. Over the years, DRL have been proposed in the field of cardiology for invasive diagnostic and therapeutic procedures such as coronary angiography, percutaneous transluminal coronary angioplasty (PTCA), and electrophysiology procedures [9-11]. In particular, European DRL for PTCA procedures have been proposed, with these levels differing according to the complexity of the procedure [10].

Here we propose local DRL for two types of neuroradiological procedures, one diagnostic (cerebral angiography) and one therapeutic (cerebral embolisation). Cerebral angiography refers to investigation of head and brain arteries, whereas cerebral embolisation is therapeutic obliteration (coiling) of intra-cranial aneurysms and arteriovenous malformations (AVM). Selective investigations in the case of cerebral aneurysms are carried out on four axes (internal carotid and vertebral arteries), whereas those for AVM involve six axes (internal carotid, external carotid and vertebral arteries).

The praxis suggested by the European Guidelines [12] is to consider as DRL the 75th percentile of the distribution, established by a dosimetric survey, of dose (KAP) or other parameters such as fluoroscopy time and number of frames. DRL are not restrictive limits, nor are they dose limits or threshold levels that define the competent performance of the operator or the equipment [6], but rather guideline levels to good practice, whose establishment and application in interventional neuroradiology must be flexible because of the complexity of the procedures. DRL are not applicable to individual patients. Comparison with DRL shall be made using mean values of a patient sample only. The main objective of DRL is their use in a dynamic and continuous process of optimization. In order to be able to define DRL it is recommended that more than 50 cases are analysed $[13,14]$. It should be noted that the DRL are typically established after a survey between different centres and not only from a single Hospital. Following the UK recommendations, as presented by Marshall [15], establishing national DRLs would require a minimum of 20 centres and at least 10 patients for each examination room, thus 200 patients minimum. Hospitals should adopt the national DRLs for use locally or establish their own DRLs based on local practice, if sufficient local data are available. The aim of this study was to propose local diagnostic reference levels (DRL) for exposure to radiation during diagnostic procedures and neuroradiological interventions such as cerebral angiography and embolisation of cerebral aneurysms (intra-cranial aneurysms and arteriovenous malformations). This study is based on data from 113 cerebral angiography procedures and 82 cerebral embolisation procedures carried out at the Department of Radiology of the Fondazione I.R.C.C.S. Policlinico San Matteo.

\section{Material and methods}

\section{Description of the pathologies and their classification}

Cerebral aneurysms are circumscribed dilations of intracranial arteries and are generally saccular. They have a proximal neck and a distal base, this latter usually with a more fragile wall that is more likely to rupture. Cerebral aneurysms occur more frequently in adults than in children and more commonly in women than in men; they can present at any age but are more common between the fourth and seventh decades of life. Aneurysms can be treated via direct surgical craniotomy or by embolisation. The choice of treatment, most suitable for the individual patient, is determined by the neurosurgeon and the neuroradiologist during the diagnostic angiographic examination. Angiography enables the aneurysmal sac to be visualised as well as any areas of thrombosis within it, and shows the position and size of the neck and its relationship to other vessels, in particular the artery of origin. Angiography is considered the gold standard for the diagnosis and follow-up of vascular malformations within the brain and, specifically, for aneurysms and AVM. The choice of treatment depends on the type of aneurysm, its site, its size and the clinical condition of the patient.

Endovascular treatment (coiling) is carried out by the controlled deployment of coils of various shapes and sizes within the aneurysmal sac in order to reduce or block the supply of blood into the aneurysm. The coils, delivered with the help of a microcatheter and released within the sac, become modelled there in such a way that they fill all the space within the aneurysm, causing its obliteration and excluding it from the arterial blood circulation (Fig. 1).

Intra-cranial aneurysms are classified according to their shape, size and anatomical site, with these characteristics 

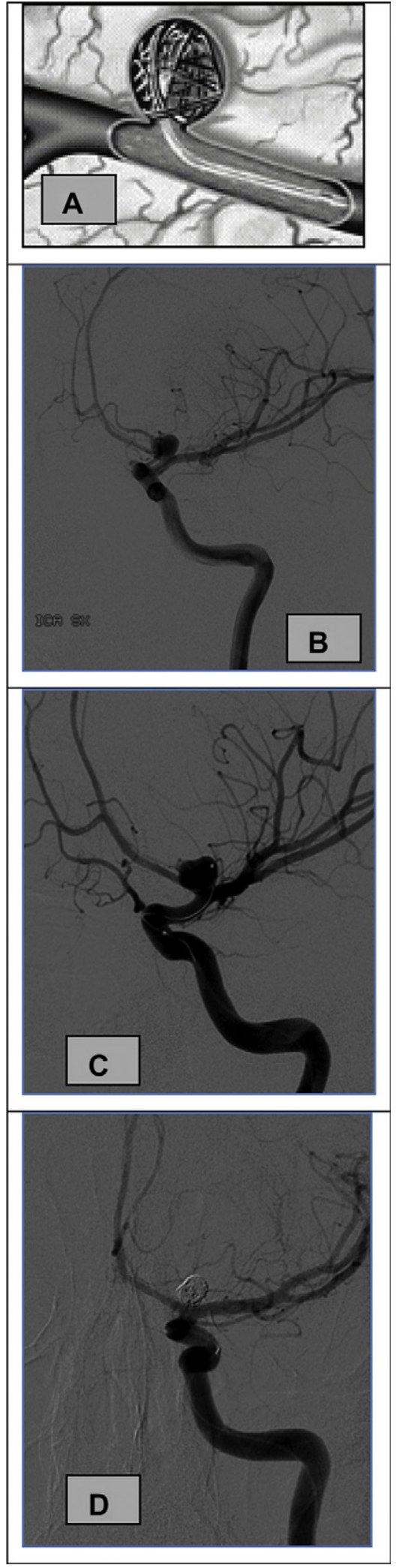

Figure 1 Endovascular coiling of ruptured intra-cranial aneurysm. Panel A: drawing of a platinum coil after deployment. Panel B: a cerebral angiogram of a saccular aneurysm of the apex of the carotid siphon. Panel C: the microcatheter within the sac of the aneurysm. Panel D: obliteration of the aneurysmal sac with a group of coils. being very important when evaluating the appropriate treatment.

The various types of intra-cranial aneurysm are described in Table 1.

Most intra-cranial aneurysms are saccular, while dissecting, fusiform, mycotic, traumatic and Charcot-Bouchard's aneurysms are less common.

Saccular intra-cranial aneurysm are generally classified on the based of the maximum diameter of the sac into three groups: "small" (aneurysmal sac less than $10 \mathrm{~mm}$ ), "large" (the maximum diameter of the sac ranges between 10 and $25 \mathrm{~mm}$ ) and "giant" (an aneurysmal sac with a diameter greater than $25 \mathrm{~mm}$ ). Small and large aneurysms were considered in this study, since there was only one case of a giant aneurysm. The strategy regarding giant aneurysms, in particular, has changed: embolisation with coils can cause a significant change in the physiology of the aneurysm, transforming it into a heavy, traumatic mass of metal. Nowadays, the often preferred strategy is that of occlusion if possible - of the feeding vessel with detachable balloons or with flow-diverter stents which occlude the neck of the aneurysm without having to fill the sac itself with coils.

Aneurysms are also classified according to their site: it is essential to determine whether the aneurysm is intradural or extradural, since these two types of aneurysms have different clinical and therapeutic implications. The origin of the ophthalmic artery provides a reliable angiographic reference point for distinguishing extradural aneurysms from intradural ones (Fig. 2).

The most frequent site of cerebral aneurysms is the circle of Willis and in particular, the anterior circle (involved in $85 \%$ of cases), at the junction of the anterior communicating artery and the anterior cerebral artery, at the origin of the of the posterior communicating artery from the internal carotid artery and at the bifurcation of the middle cerebral artery; as far as regards the posterior circle (involved in $15 \%$ of cases), the sites most commonly affected are the junction between the basilar artery and the superior cerebellar artery or anterior inferior cerebellar artery and at the origin of the posterior inferior cerebellar artery where it comes off the vertebral artery.

\section{Patient dose values}

We extracted a sample of 113 cerebral angiography procedures (in 100 patients: 61 women and 39 males) and 82 procedures of embolisation of cerebral aneurysms (in 72 patients: 46 women and 26 males; mean age 56.3 years, age range 23-79 years). The 82 embolisation procedures were performed for 72 intra-cranial aneurysms and 10 AVM. The angiographic system used was a monoplane Philips Allura 15 with a rotational programme; the system is equipped with an image intensifier with a field of view (FOV, $\Phi) 38,31,25,20$ or $17 \mathrm{~cm}$ in diameter. Enlargements with FOV of 17 and 20 are often used in cerebral embolisation procedures to have a high resolution during the placement of the Guglielmi coils. The total filtration is $3 \mathrm{~mm} \mathrm{Al}$ in the digital image acquisition mode and varies in the three pulsed fluoroscopy modes: LOW (12.5 images/s total filtration: $4 \mathrm{~mm} \mathrm{Al}+0.1 \mathrm{~mm} \mathrm{Cu})$, NORMAL $(12.5$ 


\begin{tabular}{ll} 
Table 1 & Classification of cerebral aneurysms. \\
\hline $\begin{array}{l}\text { Saccular } \\
\text { Fusiform }\end{array}$ & $\begin{array}{l}\text { Small round aneurysm, with a neck } \\
\text { Dilation of the whole wall of the vessel, usually as a result of diffuse atherosclerosis; rarely } \\
\text { ruptures } \\
\text { Aneurysm which usually results from stretching of the artery, but which can also be caused by a } \\
\text { direct lesion. Such aneurysms are more common in the extracranial carotid circulation, epiaortic } \\
\text { and extradural vessels } \\
\text { Aneurysm resulting from an infection in which septic emboli lead to the development of arteritis }\end{array}$ \\
$\begin{array}{l}\text { Mycotic } \\
\text { Charcot-Bouchard } \\
\text { Dissecting }\end{array}$ & $\begin{array}{l}\text { arteries of the basal ganglia or brainstem } \\
\text { Forms when the blood passes between the walls of the artery, separating the tunica intima from the } \\
\text { muscle layer. Can be traumatic or of a variety of other aetiologies (e.g. Marfan's syndrome) }\end{array}$ \\
\hline
\end{tabular}

images/s - total filtration: $3 \mathrm{~mm} \mathrm{Al}$ ), and HIGH (25 images/ $\mathrm{s}$ - total filtration: $4 \mathrm{~mm} \mathrm{Al}+0.1 \mathrm{~mm} \mathrm{Cu}$ ). Fluoroscopy mode mostly used is the NORMAL mode. In the fluoroscopy mode (NORMAL mode), the maximum dose rate (FOV 17) was $32 \mathrm{mGy} / \mathrm{min}$; after technical intervention was reduced to $23 \mathrm{mGy} / \mathrm{min}$. The dose per image in the radiography mode was $3 \mathrm{mGy} /$ frame for FOV 17.

The system includes an appropriately calibrated transmission chamber (KERMAX - plus-Air Kerma Product Meter Scanditronix, Schwarzenbruck). The patient dose (KAP

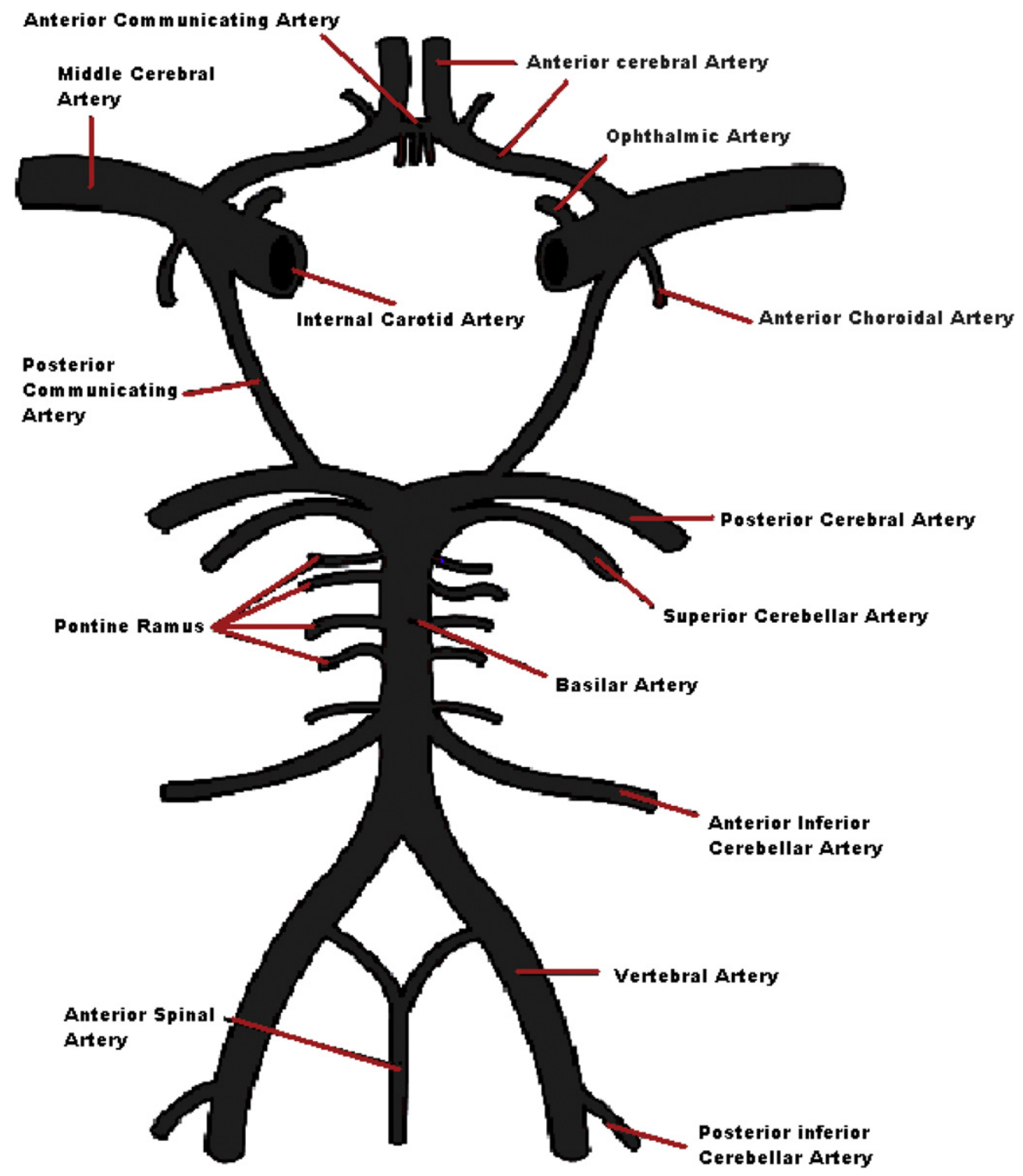

Figure 2 Cerebral circulation and the circle of Willis. 
values) presented in this report are corrected for the KAP calibration. The KAP values were not corrected by the attenuation of the table and the mattress (attenuation measured $10 \%$ ).

The other factors analysed besides the KAP were fluoroscopy time and number of frames for each procedure (both diagnostic and therapeutic) and the degree of correlation between these variables and the KAP. Third quartiles from the total dosimetric databank were calculated and proposed as provisional local DRL for KAP, fluoroscopy time and number of images.

\section{Statistical analysis}

Data are described by mean and SD if continuous and as counts and percent if categorical. Variables measuring the radiation exposure were dichotomised according to whether the exceeded or not predefined cut-offs for the DRL (>486.11 Gy $\mathrm{cm}^{2}$ for total KAP; $>46.15$ min for fluoroscopy time, $>664.75$ for number of frames). The association between exceeding DRL and location (easy/difficult access) and dimension (small/large) of the aneurysms was assessed by means of the Fisher's exact test. Odds ratio (OR) and $95 \%$ confidence intervals $(95 \% \mathrm{Cl})$ were computed with a logistic model, to measure the strength of any association. Given that it was hypothesised that a putative association between exceeding the DRL and dimension of the aneurysm would be affected by the location of the latter, prior subgroup analysis by location was programmed.

All tests were two-sided; $p$-values $<0.05$ are considered statistically significant. Stata 11 (StataCorp, College Station, TX, USA) was used for computations.

\section{Results}

We checked the correlation between KAP and the fluoroscopy time and the number of cine frames. Pearson's correlation test was used to assess whether the KAP is linearly related to the fluoroscopy time and the number of images. A $p$-value $<0.0001$ was considered statistically significant. In the case of cerebral angiography there was a good correlation between $\mathrm{KAP}_{\text {тОт }}$ and fluoroscopy time $(n=113$, $\left.r=0.7349, p<0.0001, r^{2}=0.5401\right)$ and a weaker correlation between KAP and the number of frames $(n=113$, $\left.r=0.6416, p<0.0001, r^{2}=0.4117\right)$. In the case of cerebral embolisation there was a poor correlation between KAP and fluoroscopy time $(n=82, r=0.6790, p<0.0001$, $r^{2}=0.4610$ ) and a good correlation between KAP and number of images $(n=82, r=0.7343, p<0.0001$, $r^{2}=0.5392$ ).

The number of patients in each category and the range, median, mean and standard deviation (SD), 75th percentile and 10th percentile of KAP, fluoroscopy time and number of frames for diagnostic and therapeutic procedures are given in Table $2 a$.

Figures 3 and 4 show values of KAP, histograms for cerebral angiography (113 procedures) and cerebral embolisation ( 82 procedures).

In both cases the distribution is skewed and asymmetrical with a main peak, a tail and a few extreme values. These histograms are typical of what is expected for examinations involving fluoroscopy.

When evaluating the patient dose it is important to take into account the complexity of the individual lesion and the ability of the interventional neuroradiologist to perform fine manipulation of the catheter in the region of interest also affects the total exposure time, which is directly proportional to the patient radiation dose. In the case of aneurysm embolisation (intra-cranial aneurysms), in this first phase we evaluated whether the complexity of the procedure was related to the size of the aneurysm and its location. For this purpose we re-calculated the DRL only for the intra-cranial aneurysms, excluding the AVM, and analysed the possible causes of exceeding the DRL, hypothesising that greater exposure could be related to the complexity of the intervention. Operator-dependency and variability due to the learning curve were not taken into consideration since all the procedures were carried out by the same person with more than 10 years' experience and an annual case burden of more than 50 procedures. With regards to the operator and the dependence of dose data on this variable, Verdun et al. [16] found, in the diagnostic procedures that they evaluated,

Table 2a KAP, fluoroscopy time and number of frames for diagnostic and interventional procedures.

\begin{tabular}{|c|c|c|c|c|c|}
\hline Procedure & Sample size & & $\operatorname{KAP}\left(\mathrm{Gy} \mathrm{cm}^{2}\right)$ & $\begin{array}{l}\text { Fluoroscopy } \\
\text { time (min) }\end{array}$ & $\begin{array}{l}\text { Number of } \\
\text { frames }\end{array}$ \\
\hline \multicolumn{6}{|l|}{ Diagnostic (113 procedures) } \\
\hline \multirow[t]{5}{*}{ Cerebral angiography } & \multirow[t]{5}{*}{100 patients } & Mean \pm SD & $142.10 \pm 75.51$ & $9.89 \pm 8.27$ & $242 \pm 117$ \\
\hline & & Median & 131.37 & 8.5 & 220 \\
\hline & & 3rd quartile & 180.415 & 12.3 & 316.75 \\
\hline & & Range & $33-522.87$ & $1.0-48$ & $14-584$ \\
\hline & & 10th percentile & 56 & 2.92 & 118.60 \\
\hline \multicolumn{6}{|l|}{ Interventional ( 82 procedures) } \\
\hline \multirow{5}{*}{$\begin{array}{l}\text { Cerebral embolisation (embolisation } \\
\text { for aneurysm or AVM) }\end{array}$} & \multirow[t]{5}{*}{72 patients } & Mean \pm SD & $382.8 \pm 176.21$ & $37.22 \pm 16.73$ & $574 \pm 295$ \\
\hline & & Median & 351.92 & 34.60 & 558.50 \\
\hline & & 3rd quartile & 487.42 & 46.30 & 717 \\
\hline & & Range & $120.93-943.689$ & $7.5-92.3$ & $150-1956$ \\
\hline & & 10th percentile & 192.53 & 16.96 & 256.20 \\
\hline
\end{tabular}




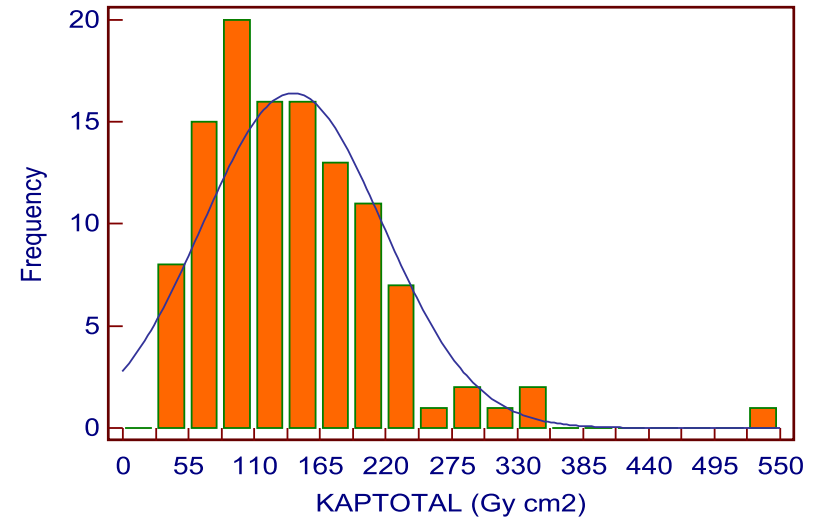

Figure 3 Histogram of total KAP values for cerebral angiography.

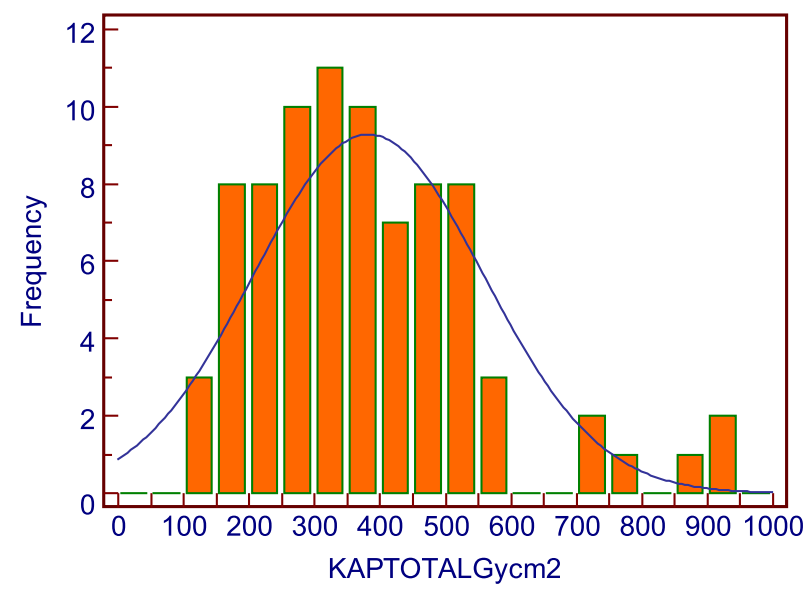

Figure 4 Histogram of total KAP values for cerebral embolisation. "the largest variability was observed for cerebral examinations in spite of the fact that these examinations were systematically performed by "senior" radiologists', that is, radiologists with more than 5 years' experience". Aroua et al. [17] observed a great variability among the parameters for this type of procedure, which is "usually performed by senior radiologists and hence the high doses are due less to a lack of training than to the complexity of the case".

The number of patients undergoing cerebral aneurysm embolisation, the range, median, mean and SD values, 3rd quartile and 10th percentile of KAP, fluoroscopy time and number of frames are given in Table $2 b$. This table shows the values of exposure parameters for the embolisation procedures of cerebral aneurysms according to the degree of complexity.

The procedures were classified on the basis of the size of the aneurismal sac (small and large) as well as according to the location of the aneurysm, assigning an index of complexity of $\mathbf{0}$ to procedures carried out on aneurysms in the apex of the basilar artery and the siphon of the interior carotid artery, and an index of complexity of $\mathbf{1}$ for those located in the following anatomical districts: anterior communicating artery, posterior communicating artery, posterior circle, posterior inferior cerebellar artery anterior inferior cerebellar artery and the pericallosal/ callosomarginal artery bifurcation. For each group we determined the degree of correlation between the parameters described above (size and position of the aneurysm) and analysed when the DRL for KAP, fluoroscopy time and number of frames were exceeded. Access to the aneurysm was defined as easy for $37(51 \%)$ of the procedures and difficult for the remaining 35 . Twenty-two (31\%) of the aneurysms were large and 50 were small. The mean KAP was $364 \mathrm{~Gy} \mathrm{~cm}^{2}$ (SD = 162), the mean fluoroscopy time was $36 \min (S D=16)$ and the number of frames per procedure was $533(\mathrm{SD}=245)$. For each of the considered

Table $2 b \quad$ KAP, fluoroscopy time and number of frames for cerebral embolisation.

\begin{tabular}{|c|c|c|c|c|c|}
\hline Procedure & $\begin{array}{l}\text { Sample } \\
\text { size }\end{array}$ & & KAP $\left(\mathrm{Gy} \mathrm{cm}^{2}\right)$ & $\begin{array}{l}\text { Fluoroscopy } \\
\text { time (min) }\end{array}$ & $\begin{array}{l}\text { Number of } \\
\text { frames }\end{array}$ \\
\hline \multicolumn{6}{|l|}{ Interventional (72 procedures) } \\
\hline $\begin{array}{l}\text { Cerebral embolisation (embolisation } \\
\text { for aneurysm) }\end{array}$ & 64 patients & $\begin{array}{l}\text { Mean } \pm \text { SD } \\
\text { Median } \\
\text { 3rd quartile } \\
\text { Range } \\
\text { 10th percentile }\end{array}$ & $\begin{array}{l}369.54 \pm 162.29 \\
349.305 \\
486.11 \\
120.93-940.383 \\
120.93\end{array}$ & $\begin{array}{l}35.86 \pm 15.64 \\
33.65 \\
46.15 \\
7.5-75 \\
8\end{array}$ & $\begin{array}{l}533 \pm 245 \\
528 \\
664.75 \\
150-1326 \\
150\end{array}$ \\
\hline \multicolumn{6}{|l|}{ Interventional (37 procedures) } \\
\hline $\begin{array}{l}\text { Cerebral embolisation (index of } \\
\text { complexity 0) }\end{array}$ & 35 patients & $\begin{array}{l}\text { Mean } \pm \text { SD } \\
\text { Median } \\
\text { 3rd quartile } \\
\text { Range } \\
\text { 10th percentile }\end{array}$ & $\begin{array}{l}396.78 \pm 165.30 \\
388.89 \\
468.06 \\
135.72-940.38 \\
219.41\end{array}$ & $\begin{array}{l}39.33 \pm 16.92 \\
40.9 \\
51,10 \\
7.5-75 \\
18.92\end{array}$ & $\begin{array}{l}597 \pm 267 \\
608 \\
775 \\
188-1326 \\
298\end{array}$ \\
\hline \multicolumn{6}{|l|}{ Interventional (35 procedures) } \\
\hline $\begin{array}{l}\text { Cerebral embolisation (index of } \\
\text { complexity 1) }\end{array}$ & 34 patients & $\begin{array}{l}\text { Mean } \pm \text { SD } \\
\text { Median } \\
\text { 3rd quartile } \\
\text { Range } \\
\text { 10th percentile }\end{array}$ & $\begin{array}{l}340.73 \pm 156.23 \\
293.19 \\
491.12 \\
120.93-797.35 \\
191.75\end{array}$ & $\begin{array}{l}32.19 \pm 13.43 \\
33 \\
40.15 \\
13.6-63.1 \\
16.28\end{array}$ & $\begin{array}{l}466 \pm 201 \\
472 \\
580 \\
150-901 \\
244\end{array}$ \\
\hline
\end{tabular}


parameters, $18(25 \%)$ procedures were classified as having exceeded the DRL (total KAP $>486.11 \mathrm{~Gy} \mathrm{~cm}^{2}$, fluoroscopy time $>46.15 \mathrm{~min}$ and number of frames $>664.75$ ). In five instances $(7 \%)$ over-exposure was recorded for all three parameters, in nine cases (13\%) for two parameters and in 21 cases $(29 \%)$ for one of them; thus, 37 procedure $(51 \%)$ could have been considered to have been performed without exceeding the DRL. The association between exceeding the DRL and location and/or size of the aneurysm is summarised in Table 3. As shown, the percentage of examinations in which the DRL were exceeded was similar for aneurysms with easy and difficult access; this percentage was higher (although not significantly so) for large aneurysms than for small aneuryms, with a two-fold increase in odds of exceeding the DRL ( $36 \%$ vs $20 \%$, OR 2.3 ). This behaviour was confirmed after stratification by location. However, the percentage of procedures in which the DRL for both fluoroscopy time and number of frames was smaller (although not significantly so) for locations with difficult access, with a two-fold and three-fold decreases in the odds of exceeding the DRL $(17 \%$ vs $32 \%$, OR 0.4 and $35 \%$ vs $14 \%, O R=0.3$, respectively), while it was slightly higher for larger aneurysms than for smaller ones. When stratifying for location, for large aneurysms the time was exceeded more frequently for those with easy access than those for which the access was difficult. Conversely, the number of frames was less frequently exceeded for larger aneurysms with easy access and more frequently for larger aneurysms to which access was difficult. Finally when considering exceeding the DRL as a whole, this was significantly less likely for aneurysms in difficult locations, with a three-fold decrease in the odds of exceeding the DRL (34\% vs 62\%, OR 0.3) and more frequent (but not significantly so) for larger aneurysms, with a more than two-fold increase in the odds of exceeding the DRL $(64 \%$ vs $42 \%$, $O R=2.4$ ). After stratification by location, larger aneurysms tended to be associated with a higher odds ratio of exceeding the DRL.

\section{Discussion}

Tables 4 and 5 present comparisons between our results and those published in the literature. In particular, Table 5 reports the results related to all the cerebral embolisation procedures (intra-cranial aneurysms and AVM) in order to be able to compare the published data. What is intended by cerebral embolisation, as specified by the various authors, is described below the table. The sample size (number of patients) is also shown in tables, in order to give an impression of the significance of the data.

For cerebral angiography procedures, the mean fluoroscopy time and the mean number of frames were lower in our patients than in the other studies: indeed, the number of frames was more than double in some other studies. The associated KAP can be up to $523 \mathrm{~Gy} \mathrm{~cm}^{2}$ with an average of $142 \mathrm{~Gy} \mathrm{~cm}^{2}$. For this type of examination, Brambilla et al. [19] reported a range of KAP from 19 to $401 \mathrm{~Gy} \mathrm{~cm}^{2}$, with an average of $158 \mathrm{~Gy} \mathrm{~cm}^{2}$ and Aroua et al. [17] reported a range from 8 to $996 \mathrm{~Gy} \mathrm{~cm}^{2}$, with an average of $121 \mathrm{~Gy} \mathrm{~cm}^{2}$.

It appears from Table $2 a$ that the fluoroscopy time is about three times longer for cerebral embolisation than

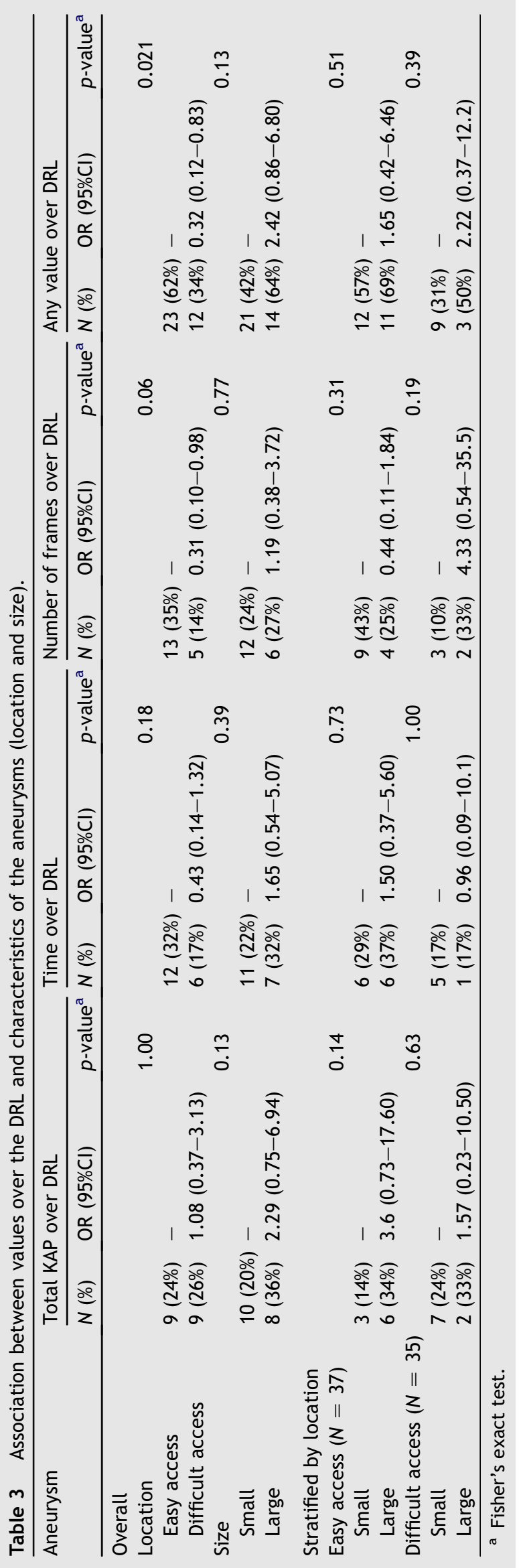


Table 4 Cerebral angiography: comparison with the literature data.

\begin{tabular}{|c|c|c|c|c|c|}
\hline Reference & $\begin{array}{l}\text { N. of } \\
\text { patients }\end{array}$ & & $\begin{array}{l}\text { Fluoroscopy } \\
\text { time (min) }\end{array}$ & $\operatorname{KAP}\left(\mathrm{Gy} \mathrm{cm}^{2}\right)$ & N. of frames \\
\hline \multirow[t]{4}{*}{ This study } & 100 & Mean & 9.89 & 142.10 & 242 \\
\hline & & Median & 8.50 & 131.37 & 220 \\
\hline & & 3rd quartile & 12.30 & 180 & 317 \\
\hline & & Range & $1-48$ & $33-523$ & $14-584$ \\
\hline \multirow[t]{4}{*}{ Verdun et al. [16] } & 91 & Mean & - & 107 & - \\
\hline & & Median & - & - & - \\
\hline & & 3rd quartile & - & 124 & - \\
\hline & & Range & - & - & - \\
\hline \multirow[t]{4}{*}{ Aroua et al. [17] } & 91 & Mean & 12.6 & 121 & 679 \\
\hline & & Median & - & - & - \\
\hline & & 3rd quartile & 15 & 125 & 480 \\
\hline & & Range & $2-85$ & $8-996$ & $32-5486$ \\
\hline \multirow[t]{4}{*}{ McParland [18] } & 28 & Mean & 12.1 & 74.1 & - \\
\hline & & Median & 9.9 & 69.6 & - \\
\hline & & 3rd quartile & 14.2 & 82.5 & - \\
\hline & & Range & $2.9-36$ & $21.4-196$ & - \\
\hline \multirow[t]{4}{*}{ Brambilla et al. [19] } & 188 & Mean & 13.7 & 158 & - \\
\hline & & Median & - & 152 & - \\
\hline & & 3rd quartile & $17.5^{\mathrm{a}}$ & 198 & - \\
\hline & & Range & - & $19-401$ & - \\
\hline \multirow[t]{4}{*}{ Bor et al. [20] } & 27 & Mean & 10.6 & 91.5 & 481 \\
\hline & & Median & - & - & - \\
\hline & & 3rd quartile & - & - & - \\
\hline & & Range & $1.7-33$ & $29.2-217.1$ & $149-1088$ \\
\hline \multirow[t]{4}{*}{ Vano et al. [21] } & 13 & Mean & - & 68.2 & - \\
\hline & & Median & - & 73.1 & - \\
\hline & & 3rd quartile & - & 82.8 & - \\
\hline & & Range & - & $16.3-136$ & - \\
\hline \multirow[t]{4}{*}{ Papageorgiou et al. [22] } & 33 & Mean & 9.8 & 128 & 254 \\
\hline & & Median & 9.6 & 104 & 247 \\
\hline & & 3rd quartile & - & - & - \\
\hline & & Range & $1.9-24.4$ & $33-261$ & $143-432$ \\
\hline \multirow[t]{4}{*}{ Vano et al. [23] } & 72 & Mean & - & - & - \\
\hline & & Median & - & - & - \\
\hline & & 3rd quartile & 12 & 107 & 550 \\
\hline & & Range & - & - & - \\
\hline
\end{tabular}

a established from the mean value.

for cerebral angiography. The average KAP related to cerebral embolisation was $382 \mathrm{~Gy} \mathrm{~cm}^{2}$, values of as high as $944 \mathrm{~Gy} \mathrm{~cm}^{2}$ have been recorded. Our KAP values are comparable to those reported in the literature.

In order to be able to compare the doses between populations, the KAP must be normalised as a function of differences in size of the patients. This normalisation is not necessary for fluoroscopy time or number of frames, because these are not influenced by body size. However, in the specific case of cerebral procedures, Miller et al. [25] showed that some parts of the body, such as the head, "where size ranges relatively little with body weight in adults, size correction and weight banding yielded values similar to the uncorrected values".

For cerebral angiography the 75th percentiles of both fluoroscopy time and number of frames in our study were lower than the proposed values; the KAP value was much higher than proposed but lower than that suggested at a local level by Brambilla et al. [19]. Vano et al. [14] proposed values of $120 \mathrm{~Gy} \mathrm{~cm}^{2}$ for KAP, 15 min for fluoroscopy time and 500 for the number of frames as preliminary European DRL for cerebral angiography. They suggested that local data should be collected from at least 50 patients and the mean value calculated for a comparison with the proposed levels. In our study the mean calculated values were $142 \mathrm{~Gy} \mathrm{~cm}$, $9.9 \mathrm{~min}$ and 242 for KAP, fluoroscopy time and number of frames, respectively. In Switzerland, Aroua et al. [17] proposed national DRL for cerebral angiography of $125 \mathrm{~Gy} \mathrm{~cm}^{2}$ for KAP, $15 \mathrm{~min}$ for the fluoroscopy time and 480 for the number of frames. According to the indications of Vano et al. [14], if we limit ourselves to comparing our mean values with those reported above, it can be seen that the fluoroscopy time and number of frames in our study were lower, whereas our KAP values were $14 \%$ higher, presumably due to the type of fluoroscopy used with different instruments (different filtration, continuous or pulsed and probably, in our case, a non-optimized value for the dose per image in radiography mode). 
Table 5 Cerebral embolisation: comparison with published data.

\begin{tabular}{|c|c|c|c|c|c|}
\hline Reference & $\begin{array}{l}\text { N. of } \\
\text { patients }\end{array}$ & & $\begin{array}{l}\text { Fluoroscopy } \\
\text { time (min) }\end{array}$ & KAP $\left(G y \mathrm{~cm}^{2}\right)$ & N. of frames \\
\hline \multirow[t]{4}{*}{ This study } & 72 & Mean & 37.22 & 382.18 & 574 \\
\hline & & Median & 34.60 & 351.91 & 558 \\
\hline & & 3rd quartile & 46.30 & 487 & 717 \\
\hline & & Range & $7.5-92.3$ & $120.93-943.68$ & $150-1956$ \\
\hline \multirow[t]{4}{*}{ Verdun et al. [16] } & 58 & Mean & - & 335 & - \\
\hline & & Median & - & - & - \\
\hline & & 3rd quartile & - & 352 & - \\
\hline & & Range & - & - & - \\
\hline \multirow[t]{4}{*}{ Aroua et al. [17] } & 52 & Mean & 36.5 & 335 & 760 \\
\hline & & Median & - & - & - \\
\hline & & 3rd quartile & 50 & 440 & 800 \\
\hline & & Range & $3.3-134$ & $24-1345$ & $60-3348$ \\
\hline \multirow[t]{4}{*}{ McParland [18] } & 5 & Mean & 34.1 & 105 & - \\
\hline & & Median & 25.5 & 85.4 & - \\
\hline & & 3rd quartile & - & - & - \\
\hline & & Range & $15.2-55.8$ & $57.2-201$ & - \\
\hline \multirow[t]{4}{*}{ Brambilla et al. [19] } & 25 & Mean & 9.9 & 329 & - \\
\hline & & Median & - & 263 & - \\
\hline & & 3rd quartile & $12.7^{\mathrm{a}}$ & 338 & - \\
\hline & & Range & - & $65-1221$ & - \\
\hline \multirow[t]{4}{*}{ Bor et al. [20] } & 21 & Mean & 48.4 & 215.7 & 1250 \\
\hline & & Median & - & - & - \\
\hline & & 3rd quartile & - & - & - \\
\hline & & Range & $5.3-140$ & $100.2-394$ & $526-1912$ \\
\hline \multirow[t]{4}{*}{ Miller et al. [24] } & 356 & Mean & 87.1 & 319.87 & 1053 \\
\hline & & Median & - & - & - \\
\hline & & 3rd quartile & - & - & - \\
\hline & & Range & $2.6-313.7$ & $3.98-1351.11$ & $71-2654$ \\
\hline
\end{tabular}

This study: intra-cranial aneurysms, AVM.

Verdun et al. [16]: cerebral embolisation - AVM, arteriovenous fistulae, intra-cranial aneurysms, tumours or haemorrhagic lesions. Aroua et al. [17]: AVM, arteriovenous fistulae, intra-cranial aneurysms, tumours or haemorrhagic lesions.

McParland [18]: cerebral embolisation.

Brambilla et al. [19]: embolisations and placement of stents.

Bor et al. [20]: cerebral AVM, aneurysms and other intra-cranial vascular pathologies.

Miller et al. [24]: neuroembolization head, AVM, aneurysms and tumours.

a Established from the mean value.

For cerebral embolisation 75th percentiles of our KAP values, fluoroscopy times and numbers of frames were comparable to those proposed by Aroua et al. [17] as Swiss national DRL. Miller et al. [25] recently proposed DRL, not corrected for body size, in the USA, for certain interventional radiology procedures including cerebral embolisation, divided into those for AVM, aneurysms and tumours. They proposed the following DRL for AVM - $550 \mathrm{~Gy} \mathrm{~cm}^{2}$ (75th percentile $505 \mathrm{~Gy} \mathrm{~cm}^{2}$ ) for the KAP, $135 \mathrm{~min}$ for fluoroscopy time and 1500 for the number of images while the corresponding proposals for aneurysms were $360 \mathrm{~Gy} \mathrm{~cm}{ }^{2}$ (75th percentile $341 \mathrm{~Gy} \mathrm{~cm}^{2}$ ), $90 \mathrm{~min}$ and 1350 .

The differences between proposed DRL can be large for a variety of reasons including differences in the definition of the type of examination and in the techniques used between centres, the complexity of the procedures (in our series the procedures were carried out in a University Hospital, in which the proportion of complex procedures may be relatively high and there is a certain number of junior radiologists undergoing training), and the series examined. The variability of the KAP as a function of the number of frames and the fluoroscopy time depends of various factors, such as the size of the fields and the angle of incidence.

We analysed how size of the aneurysmal sac and the site of the aneurysm could affect the complexity of the procedure and, in particular, the likelihood of exceeding the DRL. We found that DRL are exceeded significantly less frequently for aneurysms considered to be of difficult access, and more frequently, but not significantly so, for large aneurysms. Depending on their location, large aneurysms tend to be associated with a greater probability of exceeding the DRL. One factor that it seems must be taken into account with this type of procedure is the psychological approach of the operator to the single case. We re-calculated the DRL according to the size of the aneurysmal sac: for small aneurysms the calculated DRL for the KAP, fluoroscopy time and number of frames were $449.59 \mathrm{~Gy} \mathrm{~cm}^{2}, 43.2 \mathrm{~min}$ and 661 , respectively; for large aneurysms the corresponding DRL were $505.47 \mathrm{~Gy} \mathrm{~cm}^{2}, 53.8 \mathrm{~min}$ and 720 . In spite of the limited 
statistics, it appears that the DRL for small aneurysms were lower than those for large aneurysms. The DRL obtained depending on anatomical site were $473.06 \mathrm{~Gy} \mathrm{~cm}^{2}, 51.03 \mathrm{~min}$ and 786 for those defined as having an index of complexity 0 and $493.94 \mathrm{~Gy} \mathrm{~cm}^{2}, 44.45 \mathrm{~min}$ and 661 for those designated as having an index of complexity of 1 . In spite of these differences and considering that the DRL calculated for all the therapeutic procedures are similar to those calculated considering only intra-cranial aneurysms, we propose retaining a single set of $\mathrm{DRL}$ and, at the moment, it would seem justified to use a the DRL for embolisation procedures, even in the presence of very different clinical pictures.

Table $2 \mathrm{a}$ also shows the values for the 10 th percentile. An International Atomic Energy Agency study recommended the 10 th percentile as an 'action level' below which an investigation is needed on how to the practice is being implemented. "If mean values are greater than DRL, the entrance dose rate at the image intensifier and the dose/image should be investigated first by comparing the current values with those obtained during the acceptance test. As a second step, the examination protocol should be verified" [23].

If the mean dose at the local institution is less than the 10th percentile for the same procedure in the population used to define diagnostic reference levels, evaluation of image quality should be preferred [10]. Our values, for both types of procedure, are above the 10th percentile.

We are currently evaluating with the neuroradiologist the feasibility of defining a more complete index of complexity for the therapeutic procedures (distinct indices of complexity for AVM and intra-cranial aneurysms), as already done in the field of cardiology (e.g. for PTCA procedures). The index of complexity could take into account the age and gender of the patient, the size of the aneurysmal sac or AVM, the number of embolisations, the number and type of coils used, etc. The degree of correlation between the index of complexity and the KAP, fluoroscopy time and number of frames, will then be evaluated.

\section{References}

[1] European Union. Commission Council Directive 97/43 Euratom on health protection of individuals against the dangers of ionizing radiation in relation to medical exposure, and repealing Directive 84/466 Euratom. Off J Eur Commun 1997; L180:22-7.

[2] Wall BF. Implementation of DRLs in the UK. Radiat Prot Dosimetry 2005;114:183-7.

[3] Gray JE, Archer BR, Butler PF, Hobbs BB, Mettler FA, Pizzutiello RJ, et al. Reference values for diagnostic radiology: application and impact. Radiology 2005;235:354-8.

[4] ICRP International Commission on Radiological Protection Diagnostic reference levels in medical imaging: review and additional advice. Ann ICRP 2001;31:33-52.

[5] ICRP 103: the 2007 recommendations of the International Commission on Radiological Protection. Ann ICRP 2007;37(2-4).
[6] Radiation protection in medicine. Ann ICRP 2007;37:1-63. ICRP Publication 105.

[7] Carrol EM, Brennan PC. Radiation doses for barium enema and barium meal examinations in Ireland: potential diagnostic reference levels. Br J Radiol 2003;76:393-7.

[8] Martin CJ. A review of factors affecting patient dose for barium enemas and meals. Br J Radiol 2004;77:864-8.

[9] Neofotistou V, Vano E, Padovani R, Kotre J, Dowling A, Toivonen $\mathrm{M}$, et al. Preliminary reference levels in interventional cardiology. Eur Radiol 2003;13:2259-63.

[10] Balter S, Miller DL, Vano E, Ortiz Lopez P, Bernardi G, Cotelo $\mathrm{E}$, et al. A pilot study exploring the possibility of establishing guidance levels in X-ray directed interventional procedures. Med Phys 2008;35:673-80.

[11] Padovani R, Vano E, Trianni A, Bokou C, Hosmans H, Bor D, et al. Reference levels at European level for cardiac interventional procedures. Radiat Prot Dosimetry 2008;129:104-7.

[12] Guidance on diagnostic reference levels (DRLs) for medical exposures. European Commission Radiation Protection 109; 2000.

[13] Wall BF, Shrimpton PC. The historical development of reference doses in diagnostic radiology. Radiat Prot Dosimetry 1998;80:15-9.

[14] Vano E, Jarvinen H, Kosunen R, Bly R, Malone J, Dowling A, et al. Patient dose in interventional radiology: a European survey. Radiat Prot Dosimetry 2008;129:39-45.

[15] Marshall NW, Chapple CL, Kotre CJ. Diagnostic reference levels in interventional radiology. Phys Med Biol 2000;45:3833-46.

[16] Verdun FR, Aroua A, Trueb R, Vock P, Valley JF. Diagnostic and interventional radiology: a strategy to introduce reference dose level taking into account the national practice. Radiat Prot Dosimetry 2005;114:188-91.

[17] Aroua A, Rickli H, Stauffer JC, Schnyder P, Trueb PR, Valley JF, et al. How to set up and apply reference levels in fluoroscopy at a national level. Eur Radiol 2007;17:1621-33.

[18] MCParland BJ. A study of patient radiation doses in interventional radiological procedures. Br J Radiol 1998;71:175-85.

[19] Brambilla M, Marano G, Dominietto $M$, Cotroneo AR, Carriero A. Dose al paziente e livelli di riferimento in radiologia interventistica. La Radiologia Med 2004;107:408-18.

[20] Bor D, Cekirge S, Turkay T, Turan O, Gülay M, Ōnal E, et al. Patient and staff doses in interventional neuroradiology. Radiat Prot Dosimetry 2005;117:62-8.

[21] Vano E, Gonzales L, Fernandez JM, Guibelalde E. Patient dose values in interventional radiology. Br J Radiol 1995;68:1215-20.

[22] Papageorgiu E, Tsapaki V, Tsalafoutas A, Maurikou E, Kottou S, Orfanos A, et al. Comparison of patient doses in interventional radiology procedures performed in two large hospitals in Greece. Radiat Prot Dosimetry 2007;124:97-102.

[23] Vano E, Gonzalez L. Approaches to establishing reference levels in interventional radiology. Radiat Prot Dosimetry 2001; 94:109-12.

[24] Miller DL, Balter S, Cole PE, Lu HT, Schueler BA, Giisinger M, et al. Radiation doses in interventional radiology procedures. The RAD-IR Study. Part I: overall measures of dose. J Vasc Interv Radiol 2003;14:711-28.

[25] Miller DL, Deukwoo K, Bonavia GH. Reference levels for patient radiation doses in Interventional Radiology: proposed initial values for U.S. practice. Radiology 2009; 253:753-64. 